\title{
An Observation of Problem Spaces Based on Human-Computer Interactions
}

\author{
Liu Changyong ${ }^{1, *}$, Cheng Rengui ${ }^{1}$ and Meng Shimin ${ }^{1,2}$ \\ ${ }^{1}$ Graphical Image Lab, Wuyi University,Wuyishan 354300, Fujian, China; ${ }^{2}$ DNAgent Lab@UlinkM.com INC., Wuyis- \\ han 354300, Fujian, China
}

\begin{abstract}
Raising, analyzing and solving problems are the core competitiveness factors of innovative talent. However, to date the mechanism for problem cognition has not been elucidated and still needs to be studied. A problem space is the representation of the sum of cognitive conditions, cognitive objectives, cognitive rules, cognitive impairment, and cognitive situation, and is a high-dimensional manifold. The observation and dimensionality reduction of problem spaces are considered as problem areas. Human-computer coupled cognitive observation is a new method for studying the brain at the information level, and can also be used in the observation of problem spaces. In this paper the human-computer coupled cognitive environment is established and a problem situation is constructed. Additionally problem objects are marked, data for raising problems are collected to establish a set of problem objects, and a tree topology is selected as the structure of the low-dimensional problem space to reconstruct a problem space. It is felt that the observation, dimensionality reduction, visualization, and topologization of problem spaces provide foundations for evidence-based and dynamic studies on problem spaces, as well as providing support for teaching.
\end{abstract}

Keywords: Cognitive technology, human-computer interaction, problem space, topological manifold, visualization.

\section{INTRODUCTION}

Problem solving is an important activity in cognition and learning, and is also an important research area of cognitive science and artificial intelligence. From an educational perspective, raising, analyzing and solving problems are core competences of innovative talent, and improving students' ability to solve problems has become an important goal of modern education. In the late 1960s, modern cognitive psychology came into being. It defined problem solving as a high-level cognitive, intelligent activity and proposed a number of models, which are represented by the models of problem spaces, problem understanding and problem search proposed by the American founders of information processing psychology, A. Newell and H. A. Simon (Newell \& Simon, 1972). They believed that problem solving is divided into actual (explicit behavior in the physical world), and possible (implicit behavior in the psychological world), and referred to internal psychology as "problem spaces". A problem space is a subject's internal representation of a task environment, and not the task environment for problem solving. For example, in a problem solving experiment, the experimenter gives instructions and stimulation to the subject. In order to solve a problem, the subject has to encode the constituent objects of the problem, including conditions, objectives, rules, and the situation, into internal representations to form a problem space. A problem space is enriched and extended as the solving of the problem progresses, and the solving process consists of searching through the problem space for a path to the goal state of the problem [1]. In the problem solving process, obstacles that the search path may encounter include doubts and difficulties.

In a broad sense, when a student is learning a subject, the knowledge and skills of this subject are mapped into the cognitive psychology of the student to form a broad problem space. During learning, the student confirms knowledge by constantly contacting objects, activating a situation and searching for goals in the problem space. The search and contact in the problem space can encounter obstacles, doubts and difficulties, which intercept the search path and directly affect the student's understanding of the course. This paper focuses on studying the obstacles and doubts in the problem space of subject learning.

Currently, studies on problem spaces have been mainly carried out in the fields of cognitive psychology and pedagogy, with one of the main journals for this area being The Interdisciplinary Journal of Problem-based Learning (IJPBL) [2]. However, the research paradigms, methods and techniques of problem spaces have been more derived from psychology and pedagogy. With the development of brain science and cognitive science, the studies on problem spaces are becoming increasingly active, and the methods are also constantly developing. Consequently, the question of how to carry out empirical studies on problem spaces from the perspective of mathematical science has become an important area of study.

From the perspective of empirical scientific research, the observation of problem objects and the reconstruction of problem spaces are important factors in problem space studies. The problem space is an implicit psychological world; therefore, how can it be observed? Possible approaches include inferring problem spaces by observing students, the 
use of survey questionnaires and utilizing the teacher's own experience, such as traditional psychology and pedagogy. These methods are similar to using one's eyes to observe the sky and the universe, and thus have limited accuracy and data. It is therefore necessary to invent new technology and tools for observing problem spaces. For example, the extensive use of computers in scientific experiments and observations; but is it possible to use computers to observe problem spaces, thereby turning them into "telescopes" for this purpose? There are two problems to be solved before computers become the tools for observing problem spaces: how do computers observe the problem objects in the implicit psychological world and collect relevant data; and how do computers reconstruct problem spaces?

Currently, cognitive science is transforming to "the second generation of cognitive science" [3], which considers that cognition has the attributes of distribution and extension, and can be coupled into the environment outside the brain. Since cognition can be distributed in, and extended to the environment outside, the brain, if this environment is an information system consisting of computers, then it will be possible to observe problem spaces using computers. Therefore, there is a possible solution to the problem of observing problem spaces. From the perspective of mathematical science, the method used to observe and reconstruct problem spaces is the collection of data about high-dimensional cognitive manifolds and the selection of structures of lowdimensional cognitive manifolds to reconstruct data. In other words, the key to the reconstruction of problem spaces lies in studying the characteristics of the low-dimensional structures of cognitive manifolds. The above two points form the key areas that will be discussed in this paper.

\section{HUMAN-COMPUTER COUPLED COGNITIVE STATES}

The observation of problem objects not only requires technology, but also theoretical support. This is because problem solving occurs in the brain, while problem objects are implicit in the psychological world. Therefore, how can problem objects be observed, and how can the implicit psychological world and the problem space be expressed with mathematical models? Although brain science has been elevated to the strategic level by nations all over the world, and cognitive brain imaging has become a mainstream technology, it is still considered that the brain is an information dissipation system and should be studied simultaneously at the levels of material, ability and information, especially from the aspects of cognitive content and thinking logic. It is advised not to simply simulate the function of the brain, but to construct integrated human-computer systems and conduct research on the imaging of the cognitive structure based on human-computer integration. The late scientist Professor Qian Xuesen was a strong advocate of integrated humancomputer systems [4].

The basic task of scientific research on problem spaces is data acquisition. Traditional psychological methods usually acquire data by obtaining the language of subjects, introspection, investigation and observation, and use statistical methods to analyze data so as to explore the implicit psychological world. Current brain science primarily infers cognitive states through representations such as the energy required for the neural activity of the brain and blood activity. Obviously, the problem objects and spatial information obtained by traditional psychological methods are limited, and the methods of brain science are also insufficient to acquire data directly according to the content of problem spaces. Therefore, current studies on problem spaces are faced with a series of problems in terms of methods and tools. Therefore, what are the new methods and tools for research on problem spaces? As in scientific research, in which computers are used to observe the world from various aspects, ranging from astronomy to geography and from physics to biology, it should be considered whether the computer, which is similar to the brain, can become a tool for observing the cognitive world and consequently, a new platform for cognitive research can be established.

In cognitive psychology and brain neuroscience, the computer is more of a tool for processing data and simulating nervous systems. In the field of higher cognition it is considered that in the interactive human-computer environment the computer and the brain are mutually coupled, and the computer is an intelligent companion of the brain and develops a special interactive relationship with it. According to "the second generation of the view of cognitive science", the mechanism for human-computer interaction becomes clearer. The second generation of the view of cognitive science is renowned as being the biggest turning point of cognitive science in the last fifteen years. Its core idea is that cognition changes from being "disembodied" to being "embodied", and it proposes attributes such as cognitive situation, cognitive embodiment, cognitive distribution, and cognitive extension [5].

Distributed cognition was proposed by Jim Hollan and Ed Hutchins, and was used in the interactive humancomputer environment [6]. Distributed cognition focuses on where human cognition occurs and whether it can cross the psychological boundary of the brain, which is the cerebral cranium. This problem seems simple; it is generally understood that the physiological foundation for cognition is obviously the body. Therefore, the cerebral cranium is the psychological boundary of cognitive activity. However, distributed cognition considers that cognitive activity occurs beyond the cerebral cranium and is distributed in the environment, and that other people, technical artifacts, external representations and the environment jointly construct a cognitive environment. Distributed cognition reflects the situationality of cognition and on its basis a digital environment is built between students and intelligent devices, and the problem space in the brain is extended to the information space outside the brain.

Extended cognition is similar to distributed cognition and was proposed by Clark in 1998 [7]. Extended cognition and extended mind also emphasize that cognition can cross the boundaries of the body and mind, and that the cerebral cranium extends to the external environment of the body and mind. Clarke [7] considered that the mind is extended to cognitive objects through the coupling mechanism, which can include certain tools, media and other people. Currently, in the field of information technology, the cognitive agent model is the concrete embodiment of extended cognition. 
The theory behind extended cognition is that cognition is a dynamic coupling, and that the mind and environment are integrated through the coupling mechanism to form a new cognitive space. However, how can one judge whether cognition extends to the outside? A hypothesis is proposed by the theory of extended cognition: whether an external object is an extension of cognition can be judged by seeing if the hypothetical removal of this external constituent can reduce the behavioral ability of the cognitive system, just like the removal of part of the physiological structure of the brain.

Whether distributed cognition or extended cognition is used, there is a possibility that the cognitive space in the brain and the information space of the intelligent device connect and couple, which is called "the human-computer coupled cognitive state". Based on the human-computer coupled cognitive state, cognition in the brain is coupled with the observation outside the brain, and the computer becomes a tool for observing cognition and the problem space, and constantly acquires the information of the problem space like an astronomical telescope or a cloud chamber. Based on the new philosophical view of cognition, human-computer interaction breaks down into the brain cognitive body, coupling situation, and the information manifold, abbreviated to BSM [8], which creates a new method for observing cognition.

In this paper the authors not only obtain new technology for observing cognition from the new perspective of cognitive philosophy, but also explain the BSM mechanism on the basis of category theory. Category and morphism are mathematical theories introduced by Piaget to study the mechanism for the occurrence of cognition. On the basis of category theory, B, S, and M all are morphisms. Through the morphism coupling situation $(\mathrm{S})$, there is a cognitive natural isomorphism and a cognitive coupling transformation between the cognitive body (B) and the information manifold (M), and the following theorems are obtained:

Theorem 1. The Cognitive Natural Isomorphism between the Information Space and Cognitive Space: The morphism $\boldsymbol{f} \in \operatorname{hom}(\mathrm{B}, \mathrm{M})$ is called an equivalent $(\boldsymbol{f}: \mathrm{B} \approx \mathrm{M})$. If $\boldsymbol{f}$ has a two-sided inverse $\boldsymbol{f}^{-1}$ hom $(\mathrm{B}, \mathrm{M})$, namely if there is an equivalent cognitive morphism between the information category and cognitive category, then the objects of the cognitive category are equivalent. This is called the cognitive natural isomorphism theorem, as shown in Fig. (1).

$$
\begin{aligned}
& \operatorname{hom}(B, S) \times \operatorname{hom}(S, M) \rightarrow \operatorname{hom}(B, M) \\
& \operatorname{hom}(M, S) \times \operatorname{hom}(S, B) \rightarrow \operatorname{hom}(M, B)
\end{aligned}
$$

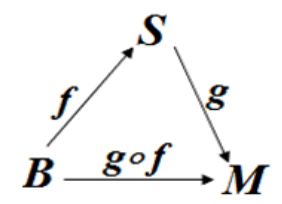

Fig. (1). The Cognitive Natural Isomorphism.

Theorem 2 The Coupled Cognitive Transformation between the Information Space and the Cognitive Space: According to the category functor principle, the cognitive functor keeps the coupled transformation among BSM, and the covariance of cognitive rules between the cognitive mor- phism inside the brain and the information manifold morphism, as shown in Fig. (2).

The Cognitive Natural Isomorphism Theorem and Coupled Cognitive Transformation Theorem ensure the unity of cognitive objects and the covariance of cognitive rules between the cognitive space and information space from the category perspective. They are the mathematical foundations for BSM cognitive observation and on the basis of BSM, problem objects and problem spaces can also be observed.

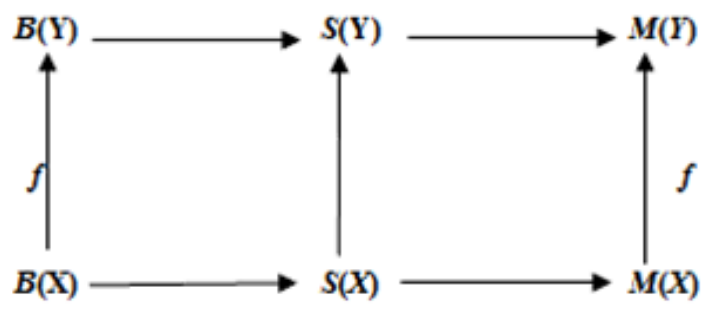

Fig. (2). The Coupled Cognitive Transformation.

\section{THE LOW-DIMENSIONAL TOPOLOGICAL STRUCTURE OF THE PROBLEM SPACE}

Suppose that a course of study, including learning objectives, processes and operations, is mapped into the psychological world to form an internal representation, namely a problem space or a problem manifold $\mathrm{P}$. There is no doubt that $\mathrm{P}$ is a high-dimensional cognitive manifold, and observation, analysis, and dimensionality reduction are problem areas or difficulties. The authors focus on observing the problems, doubts, and difficulties that exist in learning a subject, as well as the obstacles encountered during problem understanding and search, namely focusing on the obstacles in P. 1)Textbooks are scanned to obtain images and design a problem situation; 2)Students can highlight difficulties by inserting marks on the images in textbooks and raise problems. 3)The marked content is defined as the difficulty and obstacle objects in $\mathrm{P}$, called $\mathrm{p}_{\mathrm{obj}}$. $\mathrm{p}_{\mathrm{obj}}$ constitutes the problem set Q.

Topology theory is an effective method of describing a cognitive structure [9]. Suppose that the problem space is a topological structure; namely assume that $\mathrm{Q}$ is a problem set, then the family $\tau$ of subsets of Q is called a topology of Q. If it satisfies the following:

1. Both $\mathrm{Q}$ and the empty set \{\} belong to $\tau$;

2. The union of any number of members in $\tau$ is still in $\tau$;

3. The intersection of a limited number of members in $\tau$ is still in $\tau$.

If set $\tau$ satisfies the above three topological axioms, then it is called a topological space, denoted as $(\mathrm{Q}, \tau)$. On the basis of the set of problem objects, the objective of establishing a topological space of problems is to build a mathematical model of the topological space of problems for the mathematical analysis of problem spaces. As shown in Fig. (3), some elements of set Q constitute a set, which is mapped into an element of the topological space $\tau$. Currently, in cognitive psychology and educational psychology studies, problem spaces rest more on the operation of set $\mathrm{p}_{\mathrm{obj}}$, and are confined to statistical methods. Having established the topo- 
logical space $(\mathrm{Q}, \tau)$, other methods including topology analysis and topological dynamical systems will be introduced. From a manifold perspective, problem space $\mathrm{P}$ is a highdimensional manifold, and set $\mathrm{Q}$ is a point distributed in $\mathrm{P}$ and represents the local attribute of the manifold. It is now necessary to ascertain how to carry out an analysis of the high-dimensional problem manifold $\mathrm{P}$, based on the local objects and attributes of Q. Dimensionality reduction, namely reducing the high-dimensional manifold $\mathrm{P}$ to a lowdimensional manifold for analysis, is one approach. Therefore, the key lies in seeking the low-dimensional manifold structure of $\mathrm{P}$. It is also necessary to ask whether $(\mathrm{Q}, \tau)$ is a low-dimensional manifold structure of $\mathrm{P}$.

In mathematics, manifolds can be approximated by figures. In other words, manifolds and figures are isomorphic. Figure $G=(V, E)$ contains two sets: the set of vertexes $V$ and the set of sides E. The following steps should be carried out: 1)Establish the correspondence between $Q$ and the V of Figure $\mathrm{G}$ on the basis of the sample data set Q obtained from P; 2)Define the similarity and correlation of the objects of $Q$ and the side E of the Fig. 3) and Establish the correspondence between P and G. From a topological perspective, the figure corresponding to a manifold is a topology object whose topological property is reflected by the weight of the side. That is $(\mathrm{Q}, \tau)$ is a low-dimensional manifold structure of $\mathrm{P}$.

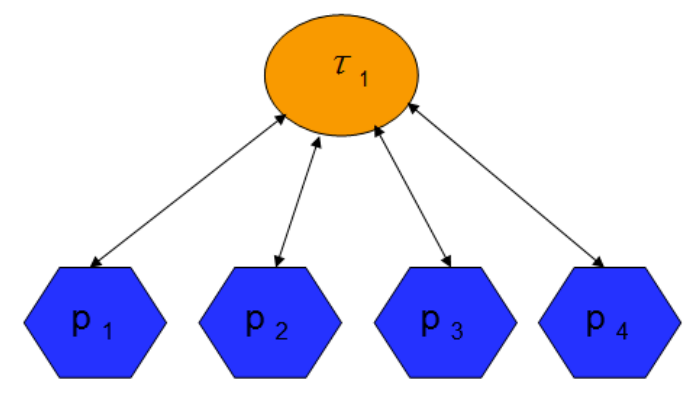

Fig. (3). A subset of the problem set Q corresponding to the element of the topological space $\tau$.

It is now necessary to ascertain what characteristics the structure of the topological problem space $(\mathrm{Q}, \tau)$ has. In other words, what are the characteristics of the topological structure of problem cognition in the brain? Simon et al. defines the structure of a problem space as a tree structure; specifically they express Q by the hierarchical tree structure. Fig. (4) is a schematic of a three-layered, three-dimensional tree topology. $\mathrm{Q}_{1}$ is used to express the collected problem set, and $\mathrm{Q}_{2}$ is used to express the abstract set based on $\mathrm{Q}_{1}$, which is also called the higher-order cognitive set of $\mathrm{Q}_{1}$, and so on, to establish a higher-order set of series $\mathrm{Q}_{\mathrm{n}}$. The same idea is used to establish the topological structure $\tau_{1}, \tau_{2}, \tau_{\mathrm{n}}$ based on the subsets of $Q_{n}$.

Using the idea of Simon et al., the tree structure is selected as the low-dimensional topological problem space. It can also be considered that course catalogues and scientific structures are all tree structures. These structures, which are implied by the environment, are naturally mapped to the cognitive word. In other words, the thinking, knowledge and cognitive structure of a human being can all be regarded as tree structures.

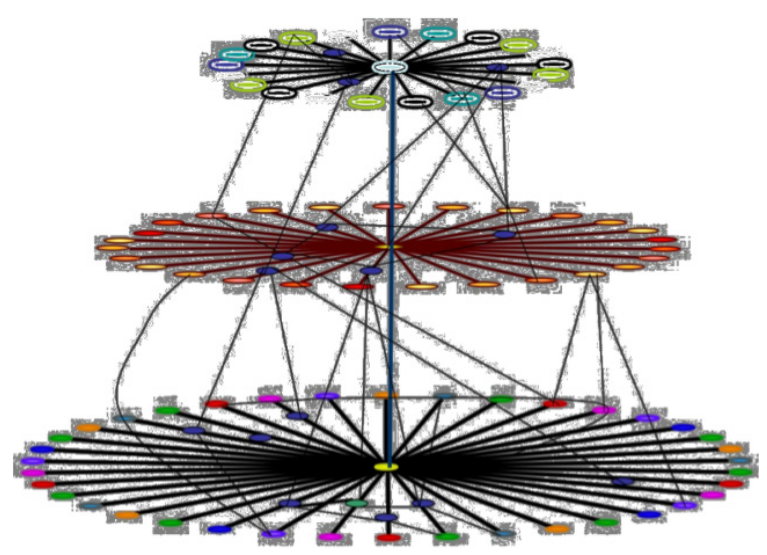

Fig. (4). The schematic of the three-layered topological problem space.

\section{AN EXAMPLE OF AN OBSERVATION OF THE PROBLEM SPACE}

Currently, ecological research is an important area of study in cognitive science and brain science and focusses on carrying out studies in natural, actual conditions outside labs. The observation of problem spaces that is based on the automation of human-computer systems can be applied to practical teaching. In teaching, students lack channels and opportunities for raising problems. For one thing, lessons have a time limit; for another, in an environment of mass psychology, individuals are under considerable psychological pressure and are afraid of raising problems. In addition, it is difficult to solve numerous problems timely and effectively. Without a deep understanding of problem spaces, teachers only construct problems that possibly exist in students' learning and are based on their experience, with a limited accuracy and poor pertinence of teaching. An observation of problem spaces is carried out as follows by referring to the textbook on office automation, A Collection of Office 2003 Test Questions, Windows XP, as an example.

The first step is to build a topological structure of problems, $\Omega .1$ Design a problem situation: scan the textbook to form a simple cognitive situation, as shown in Fig. (5); 2) Mark problem objects: students mark problems on the images according to their doubts;3)Collect problems: the computer system obtains these problems to form the set of problems Q, as shown in Table 1; 4)Construct a problem topology: establish the topological space $(\mathrm{Q}, \tau)$,based on teaching and cognitive logic, as shown in Fig. (6).

Fig. (6). is the topological structure $(\mathrm{Q}, \tau)$ of the Excel chapter, in which there is a correspondence between the points on $\tau$ and the subsets of set Q. The topological structures of the Excel, Word and PowerPoint (PPT) chapters are established to form the topological structures $\tau_{1}, \tau_{2}$, and $\tau_{3}$ respectively. Then element $\tau$ forms the new set $\mathrm{K}$, which is abstracted into the three-order topological space $(\mathrm{K}, \varnothing)$, as shown in Fig. (7). There is a correspondence between the points on $\varnothing$ and the subsets of set $K$. The problem set $Q$, and the problem topology model $\Omega$ of the first-order topology $\tau$ and the second-order topology $\varnothing$ are constructed above. The construction of $\Omega$ clearly shows the structure of problem spaces, and elevates the studies on problem spaces from the set level to the topological manifold level. 
Access 2003 实用校和

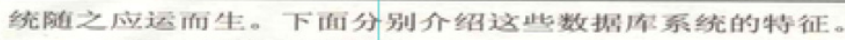

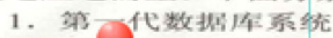

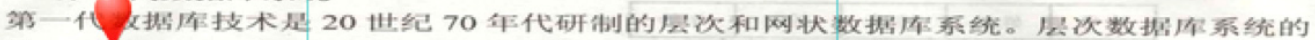

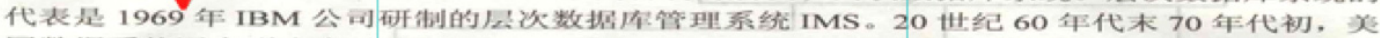

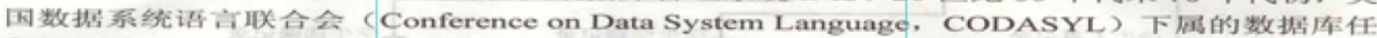

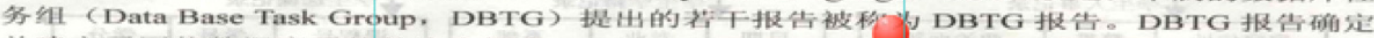

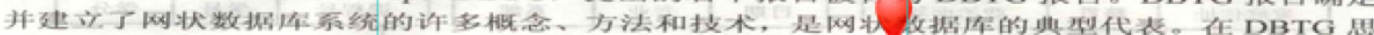

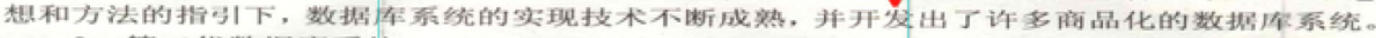

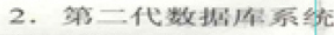

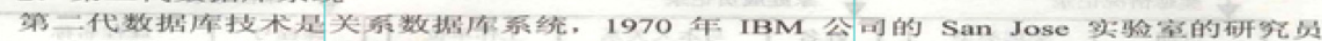

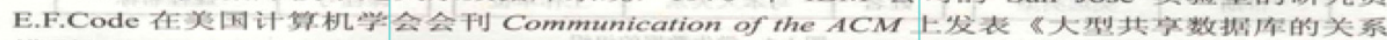
㭫烈》 (A Relational Model of Data for Shared Data Banks) 的论文. 提出了头系数据乍模型.

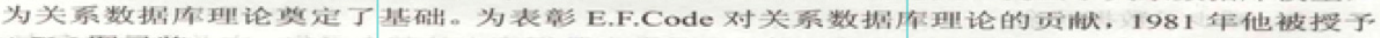
ACM R⿴囗大奖。

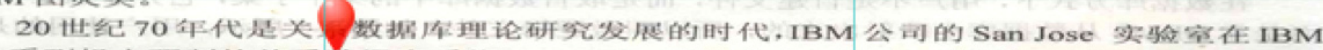

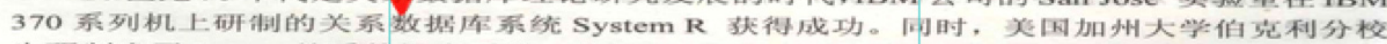

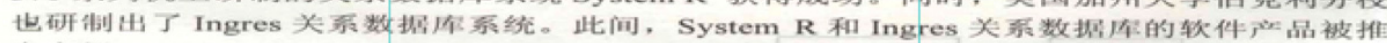
向门场。

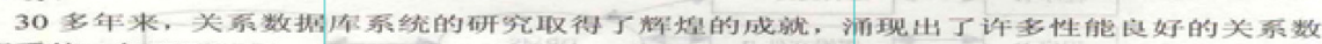

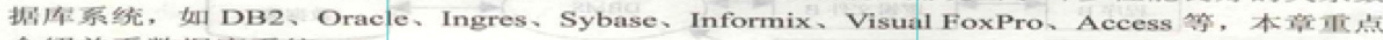

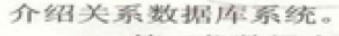

Fig. (5). Marking problems on the scanned electronic textbook

Table 1. Collecting students' problems to form set $\mathbf{Q}$.

\begin{tabular}{|c|c|c|c|c|c|c|c|}
\hline Gender & Subject & Content & $\begin{array}{l}\text { First-order } \\
\text { Category }\end{array}$ & $\begin{array}{l}\text { Second-order } \\
\text { Category }\end{array}$ & $\begin{array}{c}\text { Classification } \\
\text { of Chapters }\end{array}$ & $\begin{array}{c}\text { Subject } \\
\text { Cognition }\end{array}$ & $\begin{array}{l}\text { Cognitive } \\
\text { Ability }\end{array}$ \\
\hline Female & Chart & $\begin{array}{l}\text { How to paste a chart into the current } \\
\text { document in the form of an EXCELobject }\end{array}$ & $\begin{array}{c}\text { Insert } \\
\text { Document }\end{array}$ & Insert Object & EXCEL & $\begin{array}{l}\text { Object } \\
\text { method }\end{array}$ & $\begin{array}{c}\text { Verbal } \\
\text { information }\end{array}$ \\
\hline Female & $\begin{array}{l}\text { Use exter- } \\
\text { nal data }\end{array}$ & $\begin{array}{l}\text { How to paste a worksheet into a docu- } \\
\text { ment in the form of an excel object }\end{array}$ & $\begin{array}{c}\text { Insert } \\
\text { Document }\end{array}$ & Insert Object & EXCEL & $\begin{array}{l}\text { Object } \\
\text { method }\end{array}$ & $\begin{array}{l}\text { Verbal } \\
\text { information }\end{array}$ \\
\hline Female & Problem & $\begin{array}{c}\text { How to import an electronic sheet into a } \\
\text { worksheet }\end{array}$ & Import File & Insert Object & EXCEL & $\begin{array}{l}\text { Object } \\
\text { method }\end{array}$ & $\begin{array}{c}\text { Verbal } \\
\text { information }\end{array}$ \\
\hline Female & Convert & $\begin{array}{l}\text { How to convert rows to columns and } \\
\text { convert columns to rows }\end{array}$ & Substitute & Cell Setting & EXCEL & $\begin{array}{l}\text { Object } \\
\text { method }\end{array}$ & $\begin{array}{c}\text { Verbal } \\
\text { information }\end{array}$ \\
\hline Male & Create, edit & How to set report types & $\begin{array}{l}\text { Finance } \\
\text { Function }\end{array}$ & Function Use & EXCEL & $\begin{array}{l}\text { Object } \\
\text { method }\end{array}$ & $\begin{array}{l}\text { Verbal } \\
\text { information }\end{array}$ \\
\hline Female & $\begin{array}{l}\text { Ascending } \\
\text { sort }\end{array}$ & How to sort by "Total Sales" in Sheet 2 & Sort & $\begin{array}{c}\text { Data } \\
\text { Processing }\end{array}$ & EXCEL & $\begin{array}{l}\text { Object } \\
\text { method }\end{array}$ & $\begin{array}{l}\text { Intellectual } \\
\text { skill }\end{array}$ \\
\hline Female & Problem & $\begin{array}{l}\text { How to sort data in ascending or descend- } \\
\text { ing orders }\end{array}$ & Sort & $\begin{array}{c}\text { Data } \\
\text { Processing }\end{array}$ & EXCEL & $\begin{array}{l}\text { Object } \\
\text { method }\end{array}$ & $\begin{array}{c}\text { Verbal } \\
\text { information }\end{array}$ \\
\hline Female & $\begin{array}{l}\text { How to } \\
\text { arrange }\end{array}$ & $\begin{array}{l}\text { Sort in ascending or descending orders by } \\
\text { national index in Sheet } 2\end{array}$ & Sort & $\begin{array}{c}\text { Data } \\
\text { Processing }\end{array}$ & EXCEL & $\begin{array}{l}\text { Object } \\
\text { method }\end{array}$ & $\begin{array}{c}\text { Verbal } \\
\text { information }\end{array}$ \\
\hline
\end{tabular}




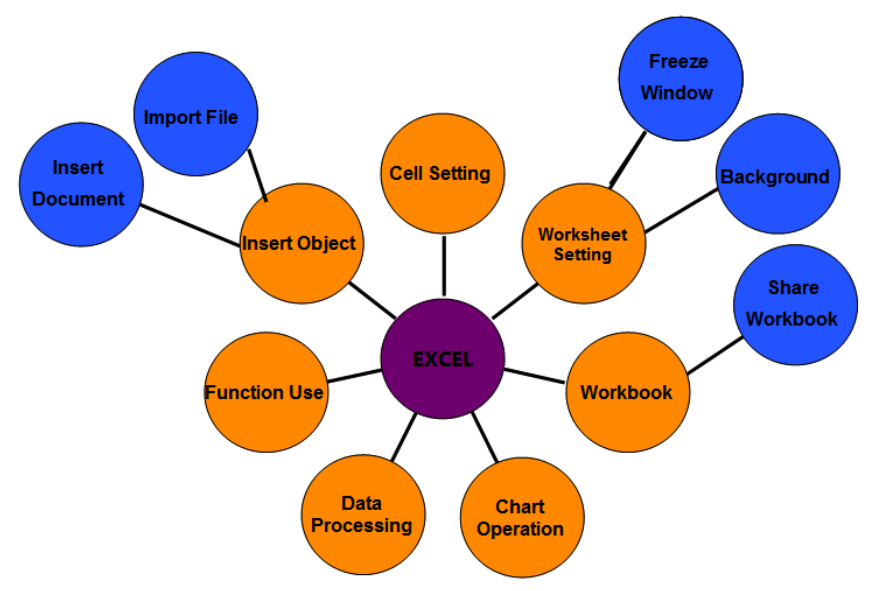

Fig. (6). Constructing EXCEL first-order problem topology based on the $\mathrm{Q}$ set $(\mathrm{Q}, \tau)$

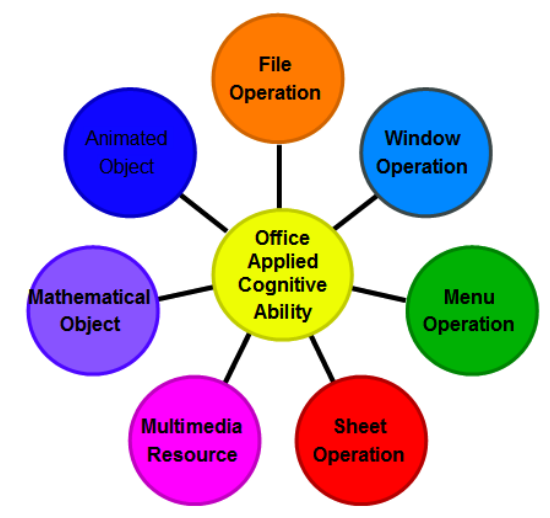

Fig. (7). Constructing Office second-order problem topology based on the $\mathrm{K}$ set $(\mathrm{K}, \varnothing)$.
The second step is to explore the cognitive logic of the objects in the problem space. Based on the analysis of $Q$ and $\Omega$, statistical and vector analysis can be carried out to obtain the valuable information in the manifold.

1.Statistical properties: on the basis of simple statistical methods, the distribution of the object $\mathrm{p}_{\mathrm{obj}}$ of the problem space (Fig. 8) and the differences in problems between males and females can be obtained.

2.Vector relationship: Exploring the vector relationship of the problem objects of a problem space is valuable work. By analyzing the data of set $\mathrm{Q}$, the correlations of the subsets of $\mathrm{Q}$ will be obtained and these correlations can be expressed by $\tau$ and $\varnothing$. For example, through Bayesian analysis [10], the relationship of the different objects in $\mathrm{Q}$ can be obtained. "Word Insert Object $\left(\mathrm{O}_{1}\right)$ - Excel Cell Setting $\left(\mathrm{O}_{2}\right)$ " are highly positively correlated. That is, if students raise a problem about $\mathrm{O}_{1}$, they will also raise a problem about $\mathrm{O}_{2}$. The same is true of "Word Picture Setting $\left(\mathrm{O}_{3}\right)$ - Word Format Setting $\left(\mathrm{O}_{4}\right)$ " and "PPT Slide Setting $\left(\mathrm{O}_{5}\right)$ - PPT Animation Setting $\left(\mathrm{O}_{6}\right)$ ". In higher orders, $\mathrm{O}_{1}$ and $\mathrm{O}_{3}$ belong to "Object Operation". These implicit relationships between objects are difficult to be identified solely on the basis of teachers' experience. Having constructed problem spaces and topological models, they can be explored through machines. Vectors are the foundation for mathematical research, and introducing vectors to $\Omega$ makes it possible to analyze the topological dynamics and cognitive logic of problem spaces.

\section{CONCLUSION}

On the basis of the cognitive natural isomorphism theorem and the coupled cognitive transformation theorem, which exist in the environment of coupled cognitive states, the computer becomes a tool for observing problem spaces.

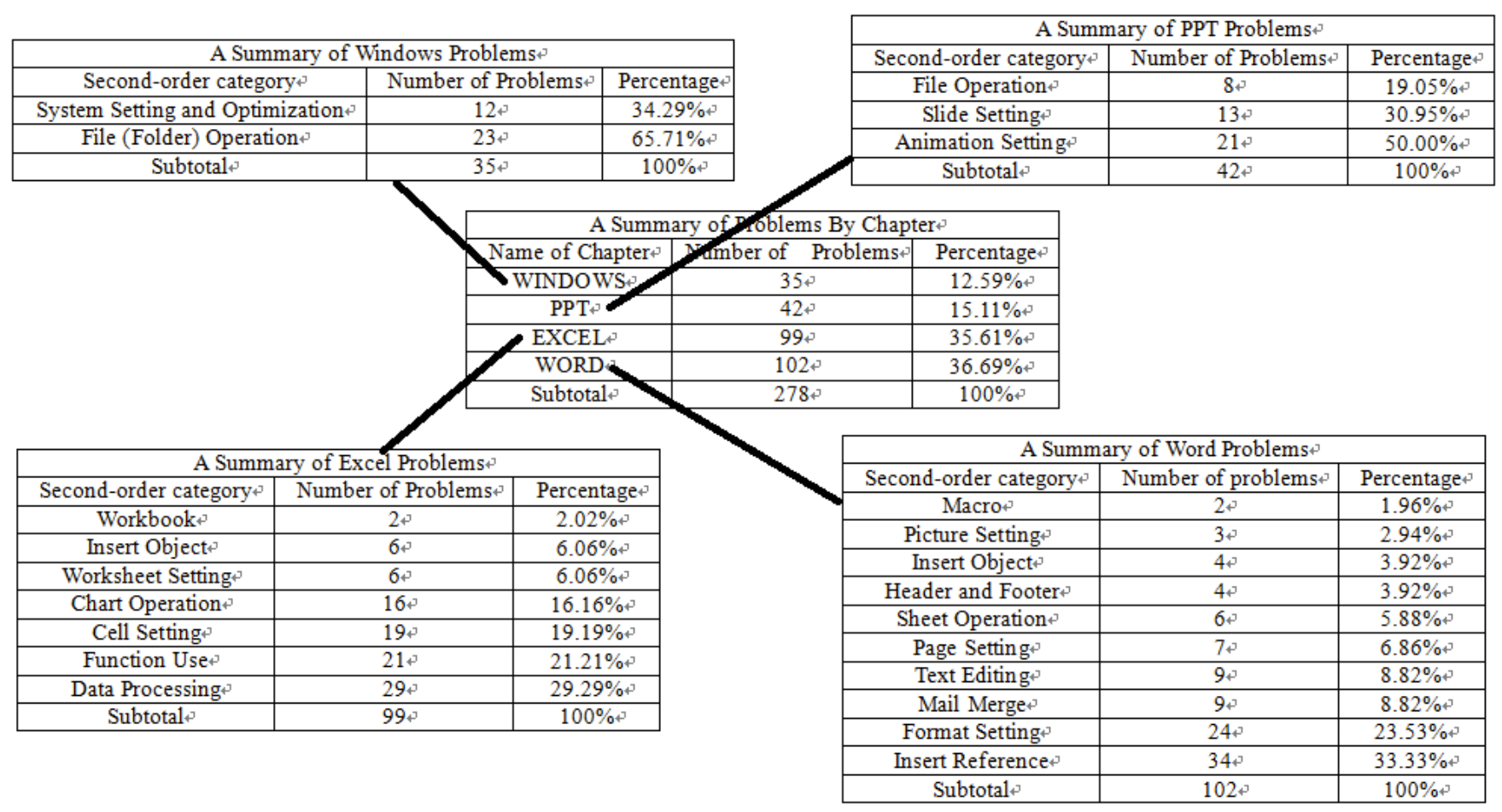

Fig. (8). The statistical properties of the problem space. 
By obtaining the difficulty and barrier objects in the highdimensional problem space through problem marking, the tree structure was selected as the low-dimensional manifold structure of the problem space, and the problem space was reconstructed and visualized. On the basis of the topological problem space, empirical studies can be carried out to statistically process the attributes of problem objects and explore their vector relationships. Future studies will be carried out on the fine structure of topological problem spaces, and the topological transitivity and topological dynamical systems of problem spaces.

\section{CONFLICT OF INTEREST}

The authors confirm that this article content has no conflict of interest.

\section{ACKNOWLEDGEMENTS}

This study was supported by science and technology funds from the Education Department of Fujian Province The Development and Implementation of the Vectorization Systems of Visual Situation Interfaces (JA12321) and The Research on the Visualization Technology of Problem Spaces Based on Human-Computer Interaction (JA13318) and The Special Fund for Industry Development and Scien- tific Research in Nanping, Fujian (N2011WZ04) and the Key Scientific Project Fund in Nanping, Fujian (N2012Z06-7).

\section{REFERENCES}

[1] W. Yuan, "Research review on problem solving abroad and its teaching meaning," J. Psychol. Sci., vol. 34, pp. 636-641, 2011. (In Chinese)

[2] http://docs.lib.purdue.edu/ijpbl/

[3] Q. Li, "Cognitive revolution and second-generation cognitive science," Acta Psychol. Sin, vol. 40, pp. 1306-1327, 2008. (In Chinese).

[4] R. Dai, "Man-computer cooperative intlligent science and intelligent technology," Eng. Sci., vol. 6, pp. 24-28, 2004.

[5] X. Yu, "The Systematic Study on the Cognitions-From the Perspective of Distributed Cognition," The Faculty of Humanities, Zhejiang Unviersity 2, 2010 (In Chinese).

[6] J. Hollan, E. Hutchins, and D. Kirsh, "Distributed Cognition: Toward a new foundation for human-computer interaction research," ACM Trans. Comput.-Hum. Interact., vol. 7, pp. 174-196, 2000.

[7] A. Clark, Supersizing the Mind. 2008 by Oxford University Press, Inc: 2008 , pp. 3-43.

[8] S. Meng, C. Liu. Etc, "The cognitive digital manifold based on the man-machine interactions," Comput. Inform. Tech., vol. 21, no. 49 pp. 1-8, 2013. (In Chinese).

[9] S. Meng, R. Cheng, Y. Liu, "Cognitive topology mapping based on human-computer interaction," J. Internet Tech. Secured Trans., vol. 1, pp.123-130, Sep. 2012.

[10] L. Li, S. Wang, R. Du, "Method of dynamic Bayesian network classifiers for cognitive structure assessment," J. Central South Univ. (Science and Technology), vol. 42, pp. 615-619, 2011.

Received: September 22, 2014

Revised: November 30, 2014

Accepted: December 02, 2014

(C) Changyong et al.; Licensee Bentham Open .

This is an open access article licensed under the terms of the Creative Commons Attribution Non-Commercial License (http://creativecommons.org/licenses/by-nc/3.0/) which permits unrestricted, non-commercial use, distribution and reproduction in any medium, provided the work is properly cited. 